\title{
A NEW METHOD IN THE IDENTIFICATION OF NOISE AND VIBRATION CHARACTERISTICS OF AUTOMOTIVE DISK BRAKES IN THE LOW FREQUENCY DOMAIN
}

\author{
K. Magaswaran, A. S. Phuman Singh and M. Z. Hassan \\ Department of Automotive Engineering, Faculty of Mechanical Engineering, \\ Universiti Teknikal Malaysia Melaka, \\ Durian Tunggal, 76100 Melaka, Malaysia, \\ Email: kumaresanmagaswaran@gmail.com
}

\begin{abstract}
Noise and vibration characterization is an important benchmark to reduce brake noise. Brake noise and vibration measurement is commonly done on an actual vehicle or on a brake dynamometer. A full scale brake dynamometer takes into account the attached mass which resembles the mass of a quarter scale vehicle. This paper proposes a testing method which eliminates the need for attached masses. This is achieved through the scaling of the brake system parameters to accommodate the loss of mass and produce similar conditions to those in actual braking. The measurement of noise and vibration is measured simultaneously and an FFT is performed to identify the frequencies of noise and vibration. An experimental modal analysis (EMA) is done to obtain the frequencies which the brake system tends to produce as a validation to the proposed method. It is shown that through this method the noise and vibration characteristics of the brake system and the unstable frequencies can be identified.
\end{abstract}

Keywords: Brake noise; brake vibration; brake dynamometer; frequency domain;.

\section{INTRODUCTION}

The brake is an important safety feature in a vehicle. The introduction of hydraulically operated disk brakes on a vehicle reduces the amount of stopping power required, thus enhancing safety, but there is an issue of noise and vibration. This issue is considered serious by carmakers around the world. In Northern America alone, up to 1 billion dollars has been spent on warranty claims regarding brake noise (Akay, 2002). Brake noises are commonly classified into two categories based on their frequencies. The first is the low frequency domain which is the noise below $1 \mathrm{kHz}$, and second is the high frequency domain which is noise above $1 \mathrm{kHz}$. The low frequency domain contains types of noise such as groans, moans, hums and judders, whereas the high frequency domain contains squeal type noises (Dunlap, Riehle, \& Longhouse, 1999; Jha \& Sharma, 2013). The low frequency noise types are generally caused by the brake pad being excited by the brake rotor at the contact and it is coupled with other vehicle components (Qatu, Abdelhamid, Pang, \& Sheng, 2009), whereas the squeal noise is said to be a friction induced vibration combined with thermal and structural effects. Understanding of the brake noise and vibration phenomena and efforts to control brake noise are a continuous challenge in the automotive braking industry. Generally, brake noise is perceived as a friction-induced forced vibration (Nuawi, Ismail, Nor, \& Rahman, 2011; Patel, Gohil, \& Borhade, 2010; Rhee, Tsang, \& Wang, 1989). The 
characteristics of a braking event are complicated, as the input to the brake system varies with an unlimited number of combinations and the brake assembly itself is a set of multiple components connected with complex interfaces. Low frequency brake noise below $1 \mathrm{kHz}$ has been of particular importance recently due to advances in automotive technology in making vehicles quieter. Thus testing of the brake system is crucial at the prototype stage itself. At that stage, a real vehicle for on road testing might not be available. Therefore, brake dynamometer testing is the only option available. Tests on a brake dynamometer have been done by Bryant, Fieldhouse, Crampton, Talbot, and Layfield (2007), Hetzler and Seemann (2006) and Little, Kao, Ferdani, and Hodges (1998), but those tests were full scale and either included the vehicle mass or suspension components.

The approach used in these tests is a causal approach which tries to identify the mechanism of the produced sound. This approach is suitable to understand the mechanisms which lead to the noise. The drawback is that this method is unable to identify the noise and vibration characteristics of the brake system in a broad frequency domain. The characteristics of the noise and vibration are important to identify the unstable frequencies within the system because it is the unstable frequencies that tend to produce noise. Furthermore, the experiment conducted should yield a result as a function of brake pressure and wheel rotational speed, because these are the local parameters in the brake system, by which the dynamics of the brake system is highly influenced. Such an experiment was done by Lindberg, Hörlin, and Göransson (2013), but it was carried out under laboratory conditions using a full scale vehicle. A full scale vehicle is only available after the vehicle enters production and the test results of a full scale vehicle would contain noise from the engine, transmission, tires and various other disturbances. The sound generated during braking is basically a friction induced sound. Friction plays a role in dissipating energy in the brake system but it can also produce energy. When friction produces more energy than it dissipates, sound is generated ${ }^{1}$. In a disk brake system, the disk and pad friction pair produces sound from such instability. The disk and pad contact are what produces the friction force, which in turn causes inplane vibration of the disk (Matsuzaki \& Izumihara, 1993; Tzou, Wickert, \& Akay, 1998). This vibration exerts a periodic force with respect to disk motion on the edge of the pads as it vibrates. This excites bending mode vibration within the pads. Consequently, it causes the contact of the pad in the disk to fluctuate and excite the bending waves on the disk (Ichiba \& Nagasawa, 1993). This phenomenon is referred to as geometric coupling, which is also called geometric instability. As the pad exerts force on the disk, the disk will tilt slightly (Kubota \& Suenaga, 1998). This tilt has the potential to produce a groan noise through a stick and slip mechanism (Gouya \& Nishiwaki, 1990). All these factors combine to form a wide range of noise and vibration in a single braking event, which is expected in the experiment to identify the brake system noise and vibration characteristics.

The aim of the developed reduced scale brake dynamometer is to produce the noise and vibration characteristics of the disk brake system so as to identify the vibration frequencies which are audibly significant, in other words, to identify unstable frequencies which produce noise, without the need to consider the vehicle mass. The elimination of hardware such as vehicle suspension and attached masses is done through calculative scaling. This reduces the testing cost and eliminates the attached mass, which enables the testing of various vehicle disk brakes without extra cost or effort. The objective of this paper is to investigate the low frequency brake noise and vibration characteristics using a reduced scale brake dynamometer. 


\section{THE SCALING OF THE PARAMETERS}

The goal of the testing is to identify the characteristics of the brake noise produced. The disk and pad vibratory system is a complex interrelated forced vibration system. In a forced vibratory system, there should be a periodic excitation force. In the brake system, the force is produced by the brake pads but the periodic quality is produced by the rotation of the disk. Thus it is important to implement the same rotational speed to reflect the real vehicle. The variable that causes the excitation force is the brake pressure, thus it is to be scaled. Scaling of the pressure is necessary to produce the desired deceleration. Implementation by applying brake pressure equal to that of a real vehicle will stop the brake rotor abruptly; this makes observation and data collection more challenging. Scaling of the excitation force will decrease the amplitude of the produced noise and vibration but not the frequencies. Therefore, it is predicted that the results will show sound levels which are low in amplitude throughout the sound spectrum but with distinguishable peaks. In order to maintain a constant relationship between the scaled and full scale brake dynamometer, the energy method is used. The change of kinetic energy when the brakes are applied is calculated using Eq. (1) for the actual vehicle and Eq. (2) for the reduced scale brake dynamometer. The change in kinetic energy is taken into account because the brakes are applied to decelerate both the vehicle and the disk brake on the brake dynamometer but not to stop the vehicle and disk brake entirely. The kinetic energy is denoted by the symbol $K$ whereas its subscript indicates the conditions in which the equation is used; $m$ is the mass of the object in motion, which in this case is the quarter scale vehicle, and $v_{n}$, is the velocity. For the rotational kinetic energy, the moment of inertia of the disk is represented by $I$ and rotational velocity is denoted by $\omega_{n}$. The variables for the scaling calculations are obtained from the actual vehicle and the braking system of the vehicle that is going to be tested. Table 1 lists the parameters used for calculations of translational and rotational kinetic energy.

$$
\begin{aligned}
& K_{\text {translational }}=\frac{1}{2} m\left(v_{n}-v_{n-1}\right)^{2}, \mathrm{n}>0 \\
& K_{\text {rotational }}=\frac{1}{2} I\left(\omega_{n}-\omega_{n-1}\right)^{2}, \mathrm{n}>0
\end{aligned}
$$

Table 1. List of parameters for translational and rotational kinetic energy calculations

\begin{tabular}{cccccc}
\hline \multicolumn{2}{c}{ Translational } & & \multicolumn{3}{c}{ Rotational } \\
\hline Variable & Value & Unit & Variable & Value & Unit \\
\hline$M$ & 246.25 & $\mathrm{~kg}$ & $I$ & 0.049 & $\mathrm{kgm}$ \\
$v_{0}$ & 24.42 & $\mathrm{~m} / \mathrm{s}$ & $\omega_{0}$ & 83.77 & $\mathrm{rad} / \mathrm{s}$ \\
$v_{1}$ & 30.53 & $\mathrm{~m} / \mathrm{s}$ & $\omega_{1}$ & 104.72 & $\mathrm{rad} / \mathrm{s}$ \\
$v_{2}$ & 33.58 & $\mathrm{~m} / \mathrm{s}$ & $\omega_{2}$ & 115.19 & $\mathrm{rad} / \mathrm{s}$ \\
$v_{3}$ & 36.64 & $\mathrm{~m} / \mathrm{s}$ & $\omega_{3}$ & 125.66 & $\mathrm{rad} / \mathrm{s}$ \\
\hline
\end{tabular}

From the calculations, the ratio between the translational kinetic energy and the rotational kinetic energy is 0.02 . This value will be used as the scaling factor to scale down the pressure applied on the brake dynamometer. To determine the pressure to be applied on the brake dynamometer, the pressure applied on a real vehicle must be 
known. This is also achieved through calculations. To calculate the pressure applied on a real vehicle, deceleration, $a$ is fixed at 0.8 . The force needed to retard the motion of the vehicle is calculated from Eq. (3), where $F_{B}$ is the braking force, $m$ is the mass of the vehicle, $a$ is the determined deceleration, and $g$ is the gravitational acceleration.

$$
F_{B}=\operatorname{mag}
$$

Then the force is used to equate the torque needed by the wheels to decelerate the vehicle by using Eq. (4), where $T$ is the torque and $R$ is the tire radius.

$$
T=F_{B} R
$$

Eq. (5) shows the relation between the torque, friction force $F_{f}$ and effective radius, $r_{\text {eff }}$. The effective radius is the distance between the center of the disk brake rotor and the center of the mass of the brake pad. The friction force is dependent on the friction coefficient, $\mu$ and normal force, $F_{n}$ which is shown in Eq. (4). The integer 2 in Eq. (6) indicates the pair of brake pads within the brake system. The normal force is determined by the applied brake line pressure, $p$ on the piston area, $A_{p}$. Eq. (8) is obtained from Eq. (5) to (7). Table 2 shows the parameters used to calculate the brake pressure. The calculated pressure will be scaled accordingly and applied during the experiment.

$$
\begin{gathered}
T=F_{f} r_{e f f} \\
F_{f}=2 \mu F_{n} \\
F_{n}=p A_{p} \\
p=\frac{m a g R}{2 \mu A_{p} r_{e f f}}
\end{gathered}
$$

Table 1. List of parameters for brake pressure calculation

\begin{tabular}{ccc}
\hline Variable & Value & Unit \\
\hline $\mathrm{M}$ & 246.25 & $\mathrm{~kg}$ \\
$\mathrm{~A}$ & 0.8 & $\mathrm{~g}$ \\
$\mathrm{G}$ & 9.81 & $\mathrm{~m} / \mathrm{s}^{2}$ \\
$\mathrm{R}$ & 0.292 & $\mathrm{~m}$ \\
$\mathrm{r}_{\mathrm{eff}}$ & 0.025 & $\mathrm{~m}$ \\
$\mu$ & 0.35 & - \\
$\mathrm{A}_{\mathrm{p}}$ & 0.157 & $\mathrm{~m}^{2}$ \\
\hline
\end{tabular}

\section{BRAKE DYNAMOMETER EXPERIMENTATION}

The brake dynamometer has four parts: the first is the drivetrain of the disk brake; second is the electrical controls; third is the braking module and last is the DAQ system. The disk brakes used are from a locally made vehicle, while the rotor, caliper, pads and mountings are original equipment manufacturer (OEM) parts. The whole assembly is 
attached to the brake dynamometer frame at the points designed to hold the brake assembly. A shaft is assembled to the brake assembly which acts as a drive shaft. The shaft is supported by pillow bearings which are attached to the dynamometer frame. At the other end of the shaft, a V-type pulley is attached. This is the driven pulley which is linked with a V-belt to a drive pulley which is attached to an electric motor. The dynamometer is driven by a Siemens $4 \mathrm{~kW} 3$-phase electric motor. The drivetrain setup is shown in Figure 1. This motor has an ABB adjustable speed drive to start the motor and control its rotational speed. From this controller the initial speed, $\omega_{0}$ can be set and, as the brakes are applied, the corresponding speed can be read.

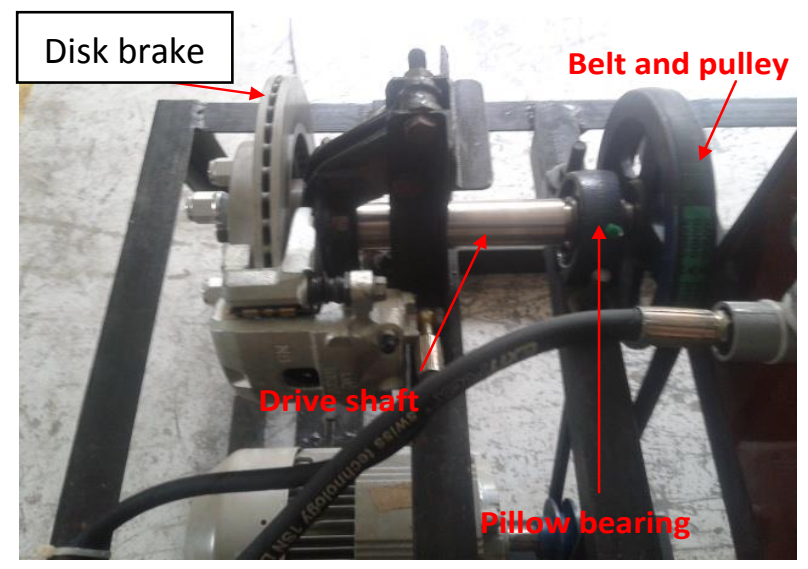

Figure 1. Drivetrain of the disk brakes

The dynamometer is powered up by a start button which starts the drive, and then when the drive is ready the motor can be run on the set desired speed. There is an emergency stop button to shut down the dynamometer immediately in case of an emergency. This is a safety feature. There are also red and green indicator lights to indicate that the motor is running or has stopped. These electrical controls are shown in Figure 2. The braking module is an OEM part of the same locally made vehicle; it has the brake pedal, the master cylinder and a brake fluid reservoir. Along the pressure line of the brake system is attached a pressure gage which is used to monitor the brake pressure applied during braking. A microphone is used to capture the noise level produced during braking and two single axis accelerometers are used to measure the vibration level. The accelerometers used are the Dytran 3225F1 and 3214A3. These accelerometers, which weigh 11 grams, are placed at the surface of the brake pad coinciding with its geometric center, whereas the microphone is placed $100 \mathrm{~mm}$ away from the brake disk coinciding with its geometric center. The microphone and the accelerometers are connected to a portable analyzer, model LDS Dactron dynamic signal analyzer PhotonII. The portable analyzer receives the electrical signal from the microphone and accelerometers and relays it to the RT Pro Photon software installed in the laptop. This software displays the sound and vibration spectrums. 


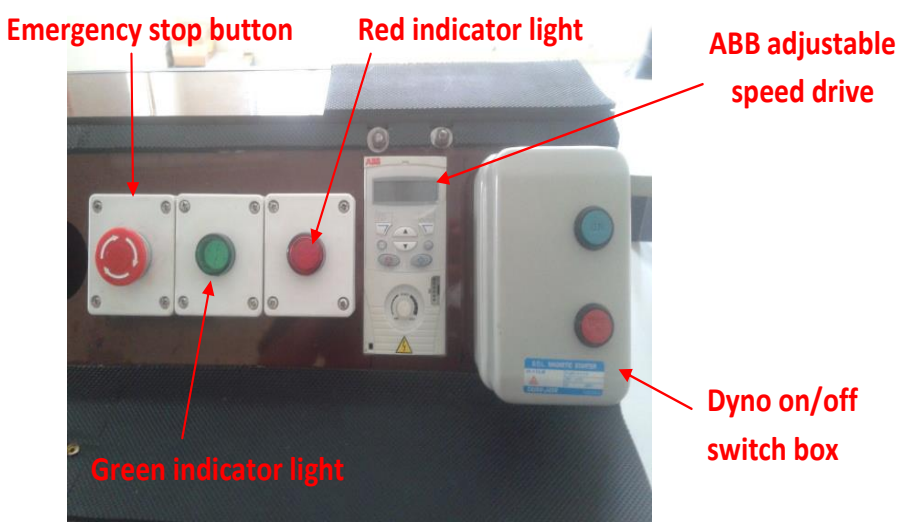

Figure 2. Electrical controls of the brake dynamometer

The measurements of the sound level and vibrations are done with reference to $0 \mathrm{~dB}$ for sound and $1 \mathrm{~mm} / \mathrm{s}^{2}$ for acceleration. The reference is chosen because if the scaled pressure that is applied in the experiment is quite low then the amplitude of the sound and vibration produced will also be low. Nonetheless, the frequency will not be affected because the periodic characteristic of the excitation force is produced by the disk rotational speed. Figure 4 shows the brake dynamometer used.

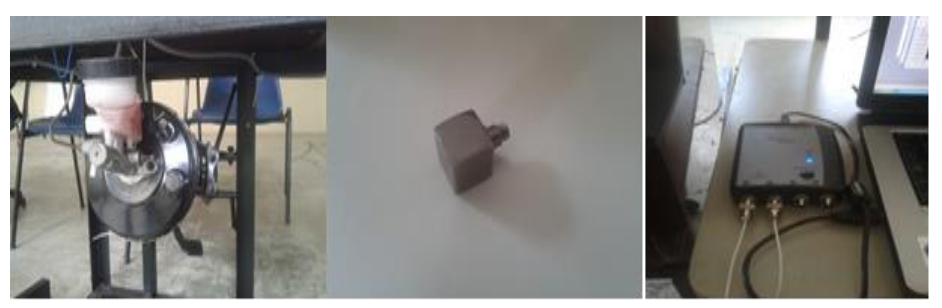

Figure 3. From left, the brake module, Dytran accelerometer and LDS Dactron portable analyzer

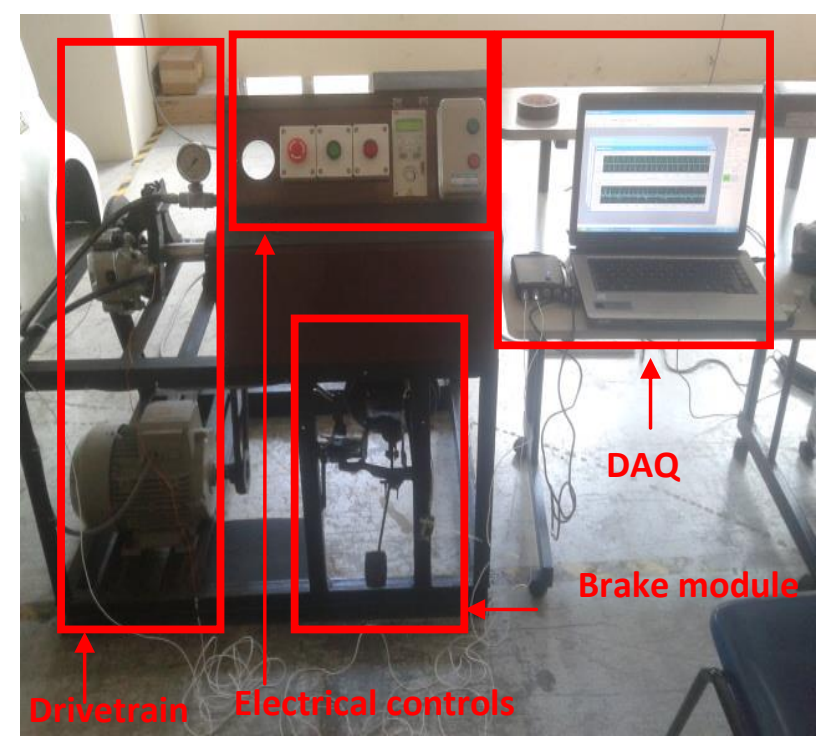

Figure 4. Full view of the UTeM small scale brake dynamometer 
The experiment is started when the main 3-phase power is turned on, followed by the green push button on the switch box. Then, 5 seconds are needed for the drive to power up. Next, the DAQ system is started. The motor is powered up and the speed is adjusted until the disk rotates at $1300 \mathrm{rpm}$. When the motor speed is set, then data recording begins. After 10 seconds have elapsed, the brake pedal is pushed immediately to reach a brake pressure of $90 \mathrm{kPa}$. The brake pedal is held at a position so that the brake pressure can be maintained until the disk brake decelerates and comes to a halt, at which point it is released immediately to avoid damage to the electric motor. The recorded data represents the whole history of events, that is, from the moment the data recording is started until the recording is stopped. Thus, the time keeping of the events is important. The times at which the data recording is started, the brake is applied, the speed of the disk brake reaches $\omega_{3}, \omega_{2}, \omega_{1}$ or $\omega_{0}$ and the brake is released are monitored. These recorded times are used to identify the windows where the FFT (Fast Fourier Transformation) is performed. The braking process is repeated extensively to scrutinize the relationship between the variables, which are the brake line pressure, disk rotational speed, sound frequencies, and sound decibels.

\section{EXPERIMENTAL MODAL ANALYSIS (EMA)}

The experimental modal analysis is conducted on the brake pad and the brake disk because these are the primary source of noise and vibration. During braking, the dynamic interaction between the brake pad and disk is what causes the noise and vibration phenomena. The EMA is carried out using the impact hammer method. The frequency spectrum obtained from the EMA of the brake and disk is shown in Figures 5 and 6, where the highest peaks in the spectra indicate the frequencies at which the pad and disk are most likely to vibrate if excited. The eight highest peaks are selected and their frequencies and amplitudes are tabulated in Table 3 for the brake pad and Table 4 for the brake disk. The frequencies and amplitudes are numerically labeled with prefix $\mathrm{n}_{\mathrm{p}}$ for brake pad and $\mathrm{n}_{\mathrm{d}}$ for brake disk. This is done for ease of reference. The frequency spectrum of the brake pad shows peaks at the higher end of the domain whereas the brake disk frequency spectrum shows peaks at the lower end of the domain. This suggests that the brake system has a tendency to vibrate in a broad frequency during braking.

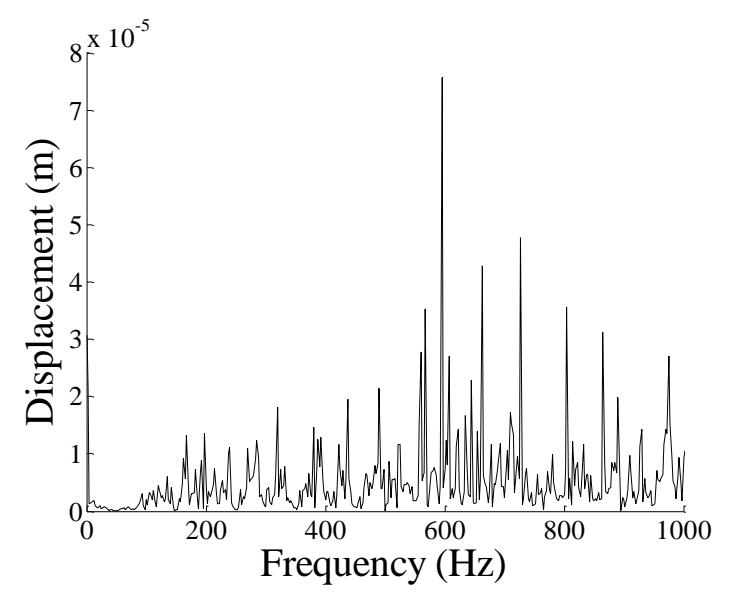

Figure 5. EMA of brake pad 


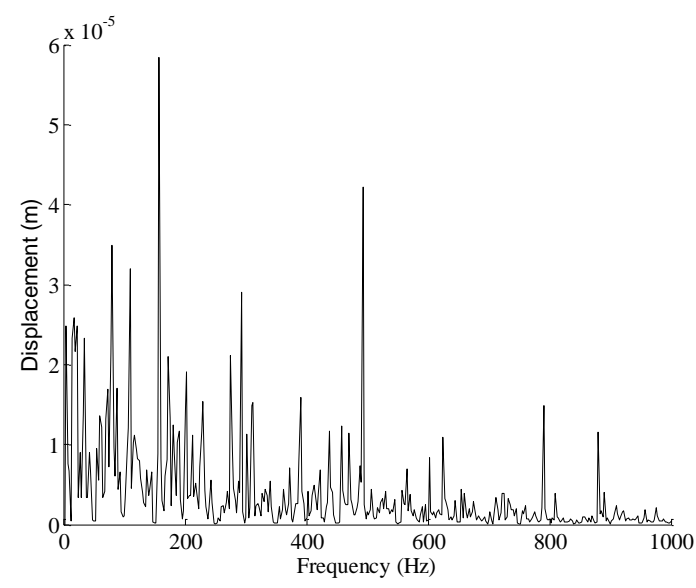

Figure 6. EMA of brake disc.

Table 3. Peak frequency and amplitude of brake pad EMA

\begin{tabular}{lll}
\hline $\mathrm{n}_{\mathrm{p}}$ & Frequency $(\mathrm{Hz})$ & Amplitude $(\mathrm{m})$ \\
\hline 1 & 490 & $2.145 \mathrm{E}-05$ \\
2 & 567.5 & $3.52 \mathrm{E}-05$ \\
3 & 595 & $7.57 \mathrm{E}-05$ \\
4 & 662.5 & $4.282 \mathrm{E}-05$ \\
5 & 727.5 & $4.764 \mathrm{E}-05$ \\
6 & 805 & $3.568 \mathrm{E}-05$ \\
7 & 865 & $3.125 \mathrm{E}-05$ \\
8 & 975 & $2.713 \mathrm{E}-05$ \\
\hline
\end{tabular}

Table 4. Peak frequency and amplitude of brake disk EMA

\begin{tabular}{cll}
\hline $\mathrm{n}_{\mathrm{d}}$ & Frequency $(\mathrm{Hz})$ & Amplitude $(\mathrm{m})$ \\
\hline 1 & 157.5 & $5.85 \mathrm{E}-05$ \\
2 & 295.5 & $2.89 \mathrm{E}-05$ \\
3 & 390 & $1.59 \mathrm{E}-05$ \\
4 & 437 & $1.16 \mathrm{E}-05$ \\
5 & 492.5 & $4.22 \mathrm{E}-05$ \\
6 & 625 & $1.57 \mathrm{E}-05$ \\
7 & 790 & $1.49 \mathrm{E}-05$ \\
8 & 880 & $1.57 \mathrm{E}-05$ \\
\hline
\end{tabular}

\section{RESULTS AND DISCUSSION}

The results are presented starting with the sound spectrum obtained during braking, followed by the vibration spectrum which was simultaneously obtained. All the peak frequencies are tabulated in Table 5; from here the two s spectra are cross-analyzed to identify unstable frequencies which could result in severe noise. The last part of the results is the validation of the scaling method. This is done by comparing the EMA frequency spectrum with the brake dynamometer experiment frequencies. Since the EMA spectrum is the frequencies at which the brake and pad system is most likely to 
vibrate, a high correlation between the EMA and brake dynamometer would validate the scaling method.

The sound spectrums at different speeds are shown in Figure 6(a) to (d) which correspond to disk rotational speeds $\omega_{3}$ to $\omega_{0}$. Figure 6 (a) shows peaks at $18 \mathrm{~Hz}, 45 \mathrm{~Hz}$, $104 \mathrm{~Hz}, 142 \mathrm{~Hz}$ and $347 \mathrm{~Hz}$ which are significantly dominant. There are also peaks at $185 \mathrm{~Hz}, 489 \mathrm{~Hz}, 855 \mathrm{~Hz}, 920 \mathrm{~Hz}$ and $963 \mathrm{~Hz}$ which are less distinguishable. As the disk decelerates as shown in Figure 6(b), the spectrum changes and the dominant peaks are at $34 \mathrm{~Hz}, 99 \mathrm{~Hz}, 142 \mathrm{~Hz}, 685 \mathrm{~Hz}$ and $837 \mathrm{~Hz}$. The peak at $920 \mathrm{~Hz}$ is still visible but has been suppressed compared to the dominant peaks. Further deceleration produced dominant peaks at $99 \mathrm{~Hz}, 142 \mathrm{~Hz}, 199 \mathrm{~Hz}, 239 \mathrm{~Hz}, 479 \mathrm{~Hz}, 683 \mathrm{~Hz}$ and $917 \mathrm{~Hz}$ and can be seen in Figure 6c. Some peaks which are dominant in Figure 6(b), such as $99 \mathrm{~Hz}, 142$ $\mathrm{Hz}$, and $683 \mathrm{~Hz}$, have maintained their dominance. Lastly, when the disk rotation speed is at $\omega_{0}$, only the peaks at $37 \mathrm{~Hz}, 75 \mathrm{~Hz}$ and $829 \mathrm{~Hz}$ can be seen, with less dominant peaks at $279 \mathrm{~Hz}, 471 \mathrm{~Hz}$ and $697 \mathrm{~Hz}$. As the deceleration progressed, the sound spectrum changed significantly. The deceleration indicates that the magnitude of the periodic quality is reducing. Due to the natural properties of the pad and disk, the amplitudes of the produced sound are also subject to change. This evidence is shown in Figure 6(a) to (d). The distinctive peaks in the spectrum show the frequency at which the sound is more dominant than the other sound frequencies. Studies such as done by Akay (2002); (Dunlap et al., 1999; Tzou et al., 1998) have listed the frequency ranges at which the sound occurs and named those specific sounds which commonly occur in the brake system. The results are in good agreement with sounds such as roughness which is $5-60 \mathrm{~Hz}$, groan which is $50-300 \mathrm{~Hz}$, judder vibration which produces an audible tone around $150 \mathrm{~Hz}$ and moan which is $100-400 \mathrm{~Hz}$. Another sound which has a frequency around $800-900 \mathrm{~Hz}$ can be classified as a low frequency squeal. The amplitudes of the sound are generally quite low, as predicted, but it is still possible to distinguish the dominant and predominant. Thus, observations are possible with the reduced scale brake dynamometer. The speed of the disk is the parameter that gives the periodic quality to this system. Thus, one frequency is dominant at one speed and another frequency is dominant at another speed, even though the pressure which is the excitation force is the same. The observation made here is that a linearly decreasing speed did not yield a linear trend in the frequencies. This represents the nonlinearity of the system's behavior.

By analyzing the spectrums of the vibration and sound together, unstable frequencies within the system can be identified. By looking at the figures for the sound spectrum and its corresponding vibration spectrum alone, the relations of the frequencies are not obvious. After extraction and tabulation of the frequencies, a clearer relation can be seen between the sound and vibration frequencies. In a braking event, the system vibrates across a broad frequency range, but only unstable frequencies are audibly significant. This is why the sound spectrum and the vibration spectrum don't relate directly. The spectrums only relate through the unstable frequencies which produce noise. Table 6 shows the sound frequencies which relate to the vibration frequencies at a difference of less than $6 \%$. These are the frequencies which have a tendency to become unstable and lead to severe noise. The unstable frequencies are unique to specific brake systems. The number of these instabilities is also dependent on the speed of the brake disk: the speed of $\omega_{3}$ and $\omega_{0}$ only showed a pair of frequencies each, whereas the speed of $\omega_{2}$ and $\omega_{1}$ showed five pairs of frequencies. This shows that there is a threshold where the conditions are right for the brake system to exhibit instability. 


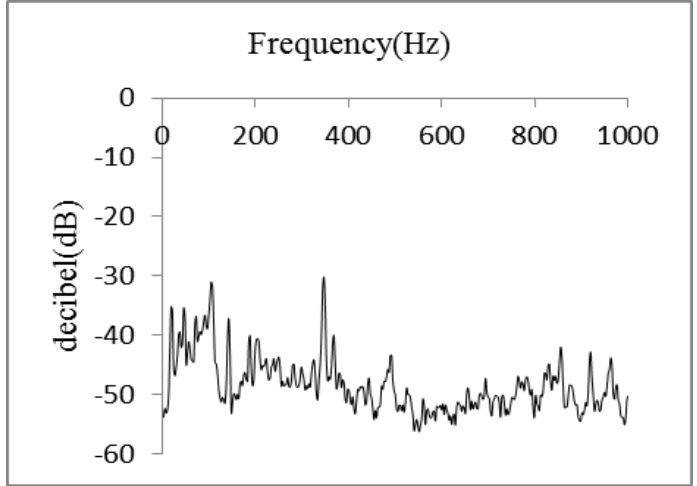

(a) Sound at $\omega_{3}$

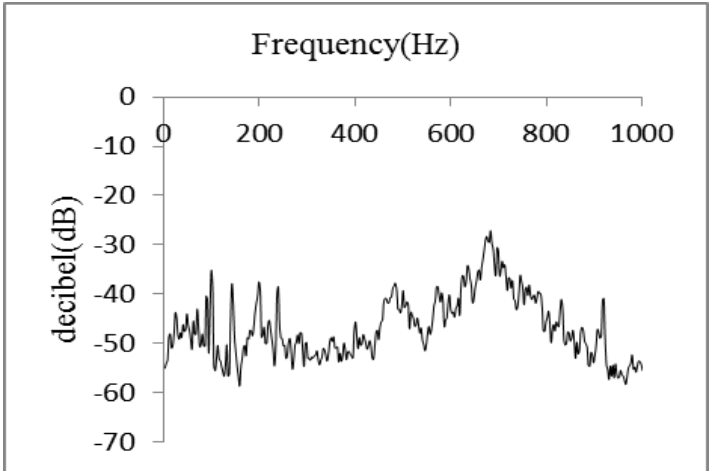

(c) Sound at $\omega_{1}$

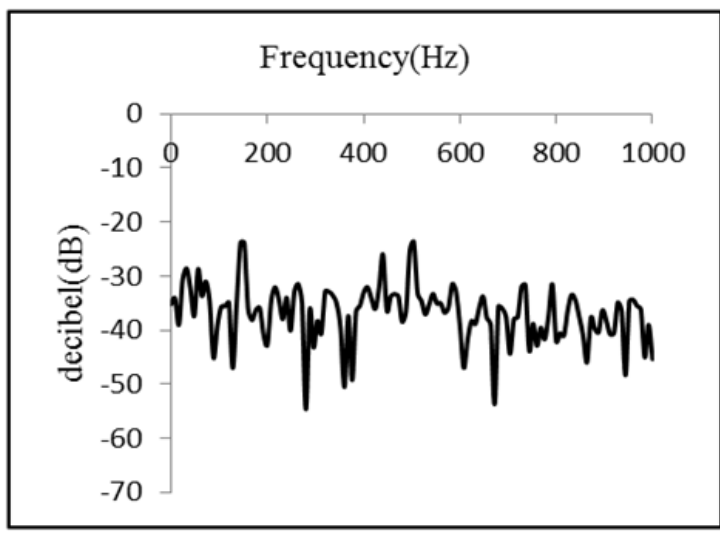

(e) Vibration at $\omega_{3}$

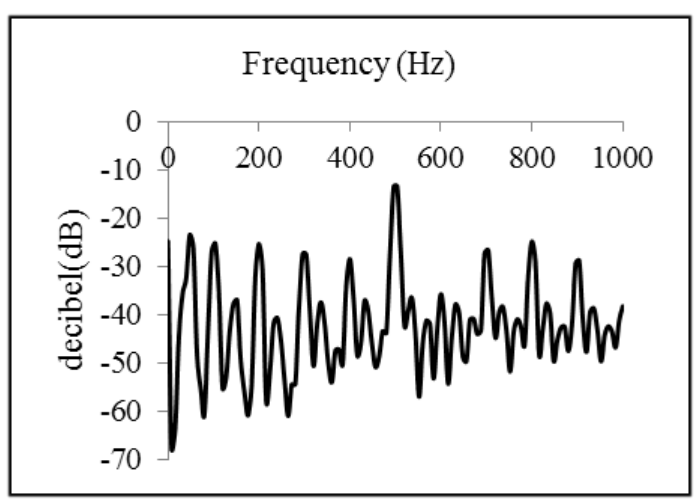

(f) Vibration at $\omega_{1}$

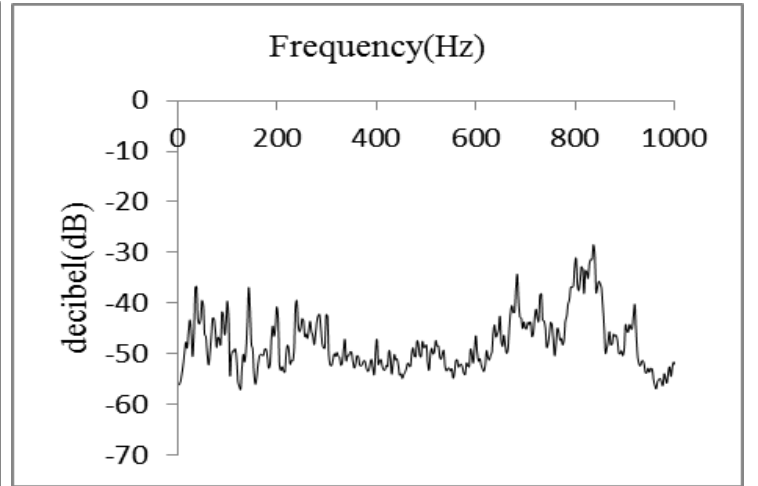

(b) Sound at $\omega_{2}$

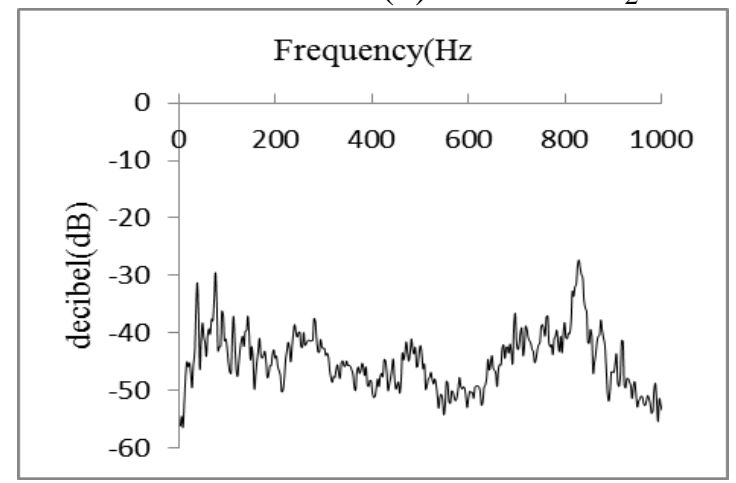

(d) Sound at $\omega_{0}$

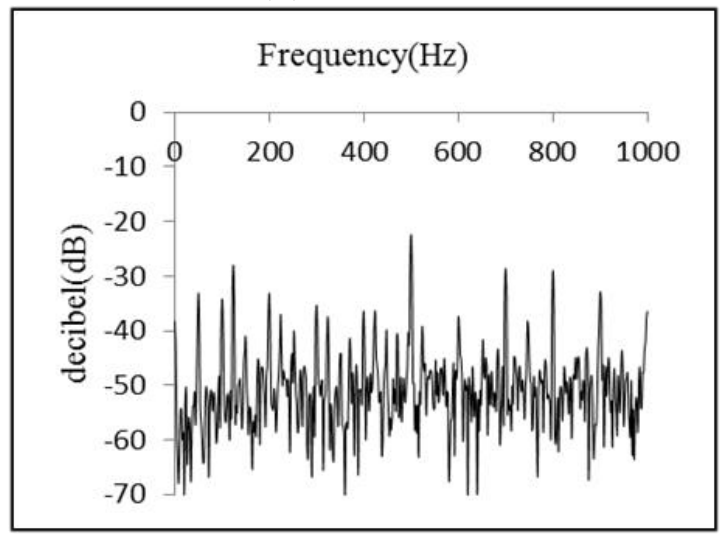

(f) Vibration at $\omega_{2}$

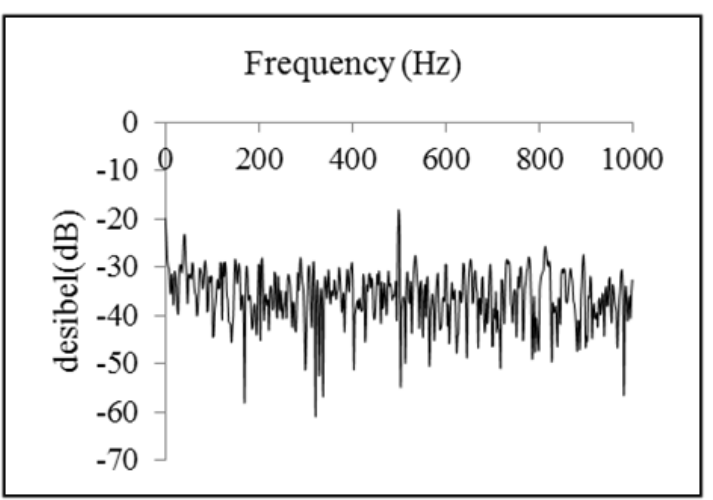

(g) Vibration at $\omega_{0}$

Figure 6. Sound and vibration spectrum for various frequencies 
Table 5. Peak values for sound spectrum and vibration spectrum

\begin{tabular}{|c|c|c|c|c|c|c|c|}
\hline \multicolumn{4}{|c|}{$\begin{array}{l}\text { Peak values for sound spectrum } \\
(\mathrm{Hz})\end{array}$} & \multicolumn{4}{|c|}{$\begin{array}{l}\text { Peak values for vibration spectrum } \\
(\mathrm{Hz})\end{array}$} \\
\hline$\omega_{3}$ & $\omega_{2}$ & $\omega_{1}$ & $\omega_{0}$ & $\omega_{3}$ & $\omega_{2}$ & $\omega_{1}$ & $\omega_{0}$ \\
\hline 18 & 34 & 99 & 37 & 144 & 50 & 48 & 40 \\
\hline 45 & 99 & 142 & 75 & 440 & 100 & 96 & 500 \\
\hline 104 & 142 & 685 & 829 & 496 & 124 & 144 & \\
\hline 185 & 685 & 837 & & & 150 & 200 & \\
\hline 347 & 837 & 920 & & & 200 & 232 & \\
\hline 489 & 920 & & & & 224 & 296 & \\
\hline 855 & & & & & 252 & 336 & \\
\hline 920 & & & & & 300 & 400 & \\
\hline \multirow[t]{15}{*}{963} & & & & & 324 & 432 & \\
\hline & & & & & 350 & 496 & \\
\hline & & & & & 370 & 696 & \\
\hline & & & & & 400 & 800 & \\
\hline & & & & & 424 & 896 & \\
\hline & & & & & 448 & & \\
\hline & & & & & 470 & & \\
\hline & & & & & 500 & & \\
\hline & & & & & 524 & & \\
\hline & & & & & 600 & & \\
\hline & & & & & 652 & & \\
\hline & & & & & 700 & & \\
\hline & & & & & 746 & & \\
\hline & & & & & 800 & & \\
\hline & & & & & 900 & & \\
\hline
\end{tabular}

Table 6. Unstable frequencies within the tested brake system

\begin{tabular}{llll}
\hline $\begin{array}{l}\text { Disk rotational } \\
\text { speed }\end{array}$ & $\begin{array}{l}\text { Sound } \\
\text { frequencies }(\mathrm{Hz})\end{array}$ & $\begin{array}{l}\text { Vibration } \\
\text { frequencies }(\mathrm{Hz})\end{array}$ & $\begin{array}{l}\text { Difference } \\
(\%)\end{array}$ \\
\hline$\omega_{3}$ & 489 & 496 & 1.41 \\
$\omega_{2}$ & 99 & 100 & 1 \\
& 142 & 150 & 5.33 \\
& 685 & 700 & 2.14 \\
& 837 & 800 & 4.62 \\
$\omega_{1}$ & 920 & 900 & 2.22 \\
& 99 & 96 & 3.12 \\
& 142 & 144 & 1.38 \\
& 685 & 696 & 1.58 \\
$\omega_{0}$ & 837 & 800 & 4.62 \\
& 920 & 896 & 2.67 \\
\hline
\end{tabular}

As a validation of the scaling method, the frequencies recorded in the brake dynamometer experiment are compared to the EMA frequencies. The rationale behind this is that the EMA showed the frequencies at which the brake disk and pad are most 
likely to vibrate, thus during braking these frequencies have a strong tendency to be distinct in the frequency spectrums. Table 7 shows a comparison between the EMA frequencies and brake dynamometer experiment frequencies with difference percentages. From the table it can be seen that the brake dynamometer could recreate the EMA frequencies with an average difference of $0.2 \%$. This shows a strong validation of the scaling method. Figure 8 shows the comparison graphically.

Table 7. Comparison between EMA frequencies and dynamometer experiment frequencies.

\begin{tabular}{llll}
\hline $\mathrm{n}$ & $\begin{array}{l}\text { EMA } \\
(\mathrm{Hz})\end{array}$ & $\begin{array}{l}\text { Dynamometer } \\
\text { experiment(Hz) }\end{array}$ & $\begin{array}{l}\text { Difference } \\
(\%)\end{array}$ \\
\hline 1 & 157.5 & 144 & 0.135 \\
2 & 295.5 & 296 & 0.005 \\
3 & 390 & 400 & 0.1 \\
4 & 437 & 432 & 0.05 \\
5 & 492.5 & 496 & 0.035 \\
6 & 490 & 496 & 0.06 \\
7 & 567.5 & 524 & 0.435 \\
8 & 595 & 600 & 0.05 \\
9 & 662.5 & 652 & 0.105 \\
10 & 625 & 652 & 0.27 \\
11 & 727.5 & 700 & 0.275 \\
12 & 805 & 800 & 0.05 \\
13 & 790 & 800 & 0.1 \\
14 & 865 & 800 & 0.65 \\
15 & 880 & 896 & 0.16 \\
16 & 975 & 900 & 0.75 \\
Average error & 0.2 \\
\hline
\end{tabular}

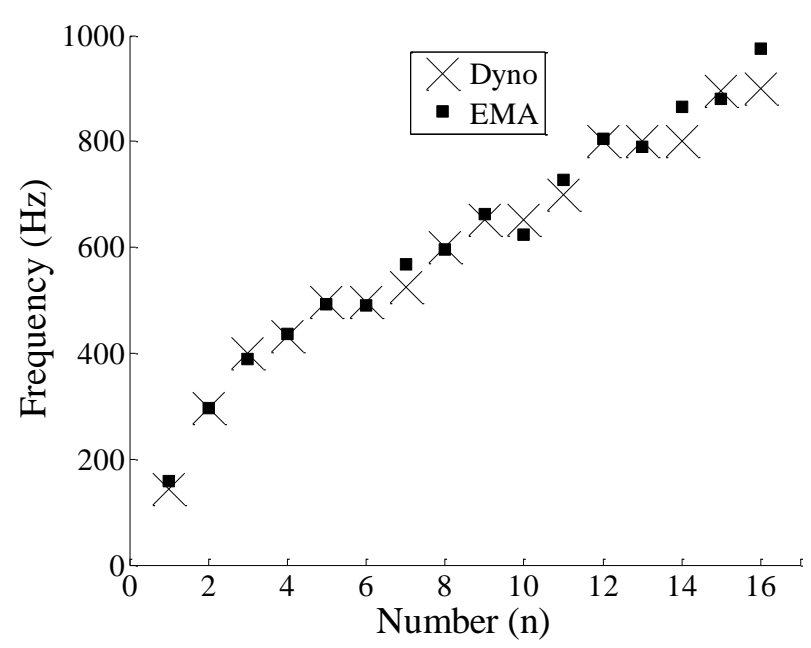

Figure 8. Comparison between EMA frequencies and dynamometer experiment frequencies. 


\section{CONCLUSIONS}

The scaling method used to eliminate a quarter scale vehicle's car mass and other components is validated using the EMA. The brake dynamometer experiment carried out showed that the scaling method yielded the EMA frequencies with high accuracy, thus validating the method. This validation of the method makes the noise and vibration characteristics obtained from the experiment practicable. From these noise and vibration characteristics, unstable frequencies can be identified. These unstable frequencies are the ones that need attention in the effort to eliminate noise from the brake system

\section{ACKNOWLEDGMENTS}

This work is supported by the Ministry of Higher Education (MoHE) of Malaysia through an FRGS research grant which was provided to the Universiti Teknikal Malaysia Melaka which provided the facilities for the research. This funding and facilities support is gratefully acknowledged.

\section{REFERENCES}

Akay, A. (2002). Acoustics of friction. The Journal of the Acoustical Society of America, 111(4), 1525-1548.

Bryant, D., Fieldhouse, J., Crampton, A., Talbot, C., \& Layfield, J. (2007). Thermal brake judder investigations using a high speed dynamometer. SAE Technical Paper.

Dunlap, K. B., Riehle, M. A., \& Longhouse, R. E. (1999). An investigative overview of automotive disc brake noise. SAE TRANSACTIONS, 108(6; PART 1), 515-522.

Gouya, M., \& Nishiwaki, M. (1990). Study on disc brake groan SAE Technical Paper 900007.

Hetzler, H., \& Seemann, W. (2006). Friction modes in low frequency disc-brake noise-experimental results and implications on modelling. Proceedings in Applied Mathematics and Mechanics, 6(1), 307-308.

Ichiba, Y., \& Nagasawa, Y. (1993). An experimental study on disc brake squeal modes and squeal exciting energy. Paper presented at the Proceedings of Asia-Pacific Vibration Conference, Kitakyushu, Japan, pp. 1-9.

Jha, S. K., \& Sharma, A. (2013). Optimal automobile muffler vibration and noise analysis. International Journal of Automotive and Mechanical Engineering, 7, 864-881.

Kubota, M., \& Suenaga, T. (1998). A study of the mechanism causing high-speed brake judder. SAE Technical Paper No. 980594.

Lindberg, E., Hörlin, N.-E., \& Göransson, P. (2013). An experimental study of interior vehicle roughness noise from disc brake systems. Applied Acoustics, 74(3), 396406.

Little, E., Kao, T.-K., Ferdani, P., \& Hodges, T. (1998). A dynamometer investigation of thermal judder. SAE Technical Paper No. 982252.

Matsuzaki, M., \& Izumihara, T. (1993). Brake noise caused by longitudinal vibration of the disc rotor. Diesel Engine, 2015, 06-22.

Nuawi, M. Z., Ismail, A. R., Nor, M. J. M., \& Rahman, M. M. (2011). Comparative study of whole-body vibration exposure between train and car passengers: A 
case study in malaysia. International Journal of Automotive and Mechanical Engineering, 4, 490-503.

Patel, C. B., Gohil, P. P., \& Borhade, B. (2010). Modeling and vibration analysis of road profile measuring system. International Journal of Automotive and Mechanical Engineering, 1, 13-28.

Qatu, M. S., Abdelhamid, M. K., Pang, J., \& Sheng, G. (2009). An overview of brake noise and vibration problems. International Journal of Vehicle Noise and Vibration, 5((1/2)), 1-35.

Rhee, S. K., Tsang, P. H. S., \& Wang, Y. S. (1989). Friction-induced noise and vibration of disc brakes. Wear, 133(1), 39-45.

Tzou, K., Wickert, J., \& Akay, A. (1998). In-plane vibration modes of arbitrarily thick disks. Journal of Vibration and Acoustics, 120(2), 384-391. 